\title{
ESCOLA E DESEJO
}

\author{
Joni Ramón Ocaño de la Fuente \\ Mag. em Educação (ORT-Uruguay)
}

\section{RESUMO}

O artigo aborda o problema da ausência do desejo e do prazer no ensino escolar contemporâneo aportando algumas reflexões sob a crise atual das escolas. A situação do ensino escolar nos dias atuais, parece ser ao mesmo tempo complexa e de fácil apresentação (mas não de fácil solução): os estudantes não aprendem ou, no melhor dos casos, aprendem cada vez em menor grau, os elementos centrais da cultura universal. Uma das hipóteses é que as escolas trabalham sem ter em conta a vontade ou o desejo de aprender e, portanto, eliminando o prazer das aulas. Se explora as possibilidades de trabalhar o desejo e o prazer nas escolas no contexto das sociedades capitalistas posindustriais incorporando alguns conceitos do pensamento deleuzeano e se busca propor uma reflexão sob a possibilidade e a licitude da "gestão pedagógica" do desejo no sistema escolar, inspirado na proposta do pedagogo francés Philippe Meirieu e incorporando a questão do poder. Além disso, parte do problema mais íntimo do ensino contemporâneo nas sociedades capitalistas ocidentais tem a ver com o que tem sido chamado de "perda do rosto" que o sistema busca impor por meio da sua ação racionalizadora sob o mundo da vida. Sem rosto não á possibilidade de chegar ao verdadeiro eu mesmo de cada um, ficando irremediavelmente perdidas parte das questões que nos definem: os afetos, os sentimentos, os sonhos e os desejos. Se analiza a questão do professor e dos condicionamentos estruturais aos que se ve submetido, assim como das posibilidades de escapar à ação racionalizadora do sistema.

Palavras-chave: desejo, prazer, pedagogia, escola.

\section{ABSTRACT}

\section{SCHOOL AND DESIRE}

This article deals with the issue of the absence of desire and pleasure in contemporary school teaching with the aim of exposing/presenting some reflections on the present crisis of the school. Nowadays the problem of school teaching seems to be very complex but at the some time easy to expose - although not so easy to salve -: students do not learn or, at best, learn progressively less about the central topics of world`s/universal culture. The school works without considering the will or the wish to learn this suppressing the pleasure in the classroom. At the core of the problem of teaching in western capitalist societies these reflections visualize the "fail to personalize" the system provoques by its way of rationalizing the concrete aspects of human reality. Without individuals there is no possibility of reaching each one's true self, being then partially lost some aspects which define us such as affections, feelings, dreams and wishes. So this article focuses on the possibility of teaching in postindustrial capitalist societie' school considering both desire and pleasure in addition to some concepts taken from Deleuze. It also proposes to think about the possibilities of a "pedagogical management" of desire in the school system inspired in the theories of the French pedagogue Philippe Meirieu and considering as well those aspects related to power.

Keyword: desire, pleasure, pedagogie, school. 


\section{ESCUELA Y DESEO}

\section{RESUMEN}

El artículo aborda el problema de la ausencia del deseo y del placer en la enseñanza escolar contemporánea con el objetivo de proponer algunas reflexiones sobre la crisis actual de las escuelas. El problema de la enseñanza escolar de nuestros días parece ser, al mismo tiempo, complejo y de fácil presentación (aunque no de fácil solución): los estudiantes no aprenden o, en el mejor de los casos, aprenden cada vez menos sobre los aspectos centrales de la cultura universal. Las escuelas trabajan sin tener en cuenta la voluntad o el deseo de aprender y, por lo tanto, eliminan el placer en las aulas. Se considera que parte del problema más íntimo de la enseñanza contemporánea en las sociedades capitalistas occidentales tiene que ver con la "pérdida del rostro" que el sistema impone a través da su acción racionalizadora sobre el mundo de la vida. Sin rostro no hay posibilidad de llegar al verdadero sí mismo de cada uno, quedando irremediablemente perdidas parte de las cuestiones que nos definen: los afectos, los sentimientos, los sueños y los deseos. Se reflexiona sobre las posibilidades de trabajar el deseo y el placer en las escuelas en el contexto de las sociedades capitalistas posindustriales, incorporando algunos conceptos del pensamiento deleuzeano y se propone la reflexión sobre las posibilidades de la "gestión pedagógica" del deseo en el sistema escolar, inspirado en la propuesta del pedagogo francés Philippe Meirieu e incorporando la cuestión del poder.

Palabras -clave: deseo, placer, pedagogía, escuela.

\section{“...ladraba interiormente el corazón de Odiseo.”}

Homero (2004, p. 204).

"Lo que debería ser dinámico se hace laborioso, lo que debería despertar el deseo se hace pesado... ¿Qué es lo que ocurre? (...) falta (...) un casi nada (...) sólo falta, en efecto, lo esencial. Y lo esencial, hay que admitirlo, es que haya un poco de deseo. (...) lo que moviliza a un alumno, lo que lo inicia en un aprendizaje, le permite asumir las dificultades, incluso las pruebas, es el deseo de saber y la voluntad de conocer."

Meirieu (2002, p. 93).

\section{Ausencia del deseo y pérdida del rostro}

En cuanto a la enseñanza escolar actual, en muchos países de la región, el diagnóstico parece ser crudo y de fácil presentación: los estudiantes no aprenden o, en el mejor de los casos, aprenden cada vez menos sobre los aspectos centrales de la cultura universal. Al parecer no hay aprendizaje porque no hay voluntad o deseo de aprender, por lo menos de aprender lo que la escuela les ofrece y de la manera como lo hace. Pareciera que la meta principal del sistema escolar es que los estudiantes aprendan los contenidos sin que los deseen; esto los pone evidentemente en una difícil situación, y no menos difícil la de los docentes quienes se las ven "machacando" saber pero no inspirando el deseo de saber con su deseo de enseñar (y de aprender). Obviamente hay excepciones. Muchos docentes quedan como prisioneros en un rol anacrónico en el que, entre otras cosas, intentan convencer de las bondades de cultivar el espíritu a través del conocimiento y la cultura - por encima de lo inmediato y lo material - siguiendo las exigencias de una 
sociedad que, sin embargo, desdeñando aquellos valores se orienta por el consumo y el capital.

Habría que considerar debidamente la voluntad y el deseo de todos y especialmente de los educandos. Tal consideración implica resignificar la educación, la cual se ha definido por la transmisión de contenidos por oposición al deseo o la voluntad y el placer. No hay que olvidar lo que Leontiev - uno de los más celebrados discípulos de Vigotsky ya había destacado hace muchos años: el cerebro es un auténtico órgano social que necesita de estímulos ambientales para su desarrollo. Sin afectividad, sin placer, el cerebro no podría alcanzar sus logros más elevados en la aventura del conocimiento, a lo sumo aspiraría a la información pero no al saber.

Mientras la información prescinde de los afectos, la sabiduría sabe cruzar con habilidad datos y sentimientos. Saber contextual y apasionado, conocimiento aterrizado donde lo abstracto y lo anecdótico se integran de cara siempre al mundo de lo sensible, la sabiduría es un conocimiento propio de la vida cotidiana que integra la ética y la estética, haciéndolas solidarias de la ciencia y la política. Saber que integra el chisme al razonamiento, y el humor a la pedagogía. (RESTREPO, 2002, p. 22).

Parece necesario, entonces, regresar al ser humano, a la persona como tal - cuyo rostro el sistema se ha encargado de borrar -, lo cual tal vez implique, entre otras cosas, reconstruir el sentido de una enseñanza que va quedando ausente en el sistema, ya que en un mundo racionalizado lo que cuenta son cada vez más las funciones y menos las personas. Ese necesario regreso al ser humano tal vez también nos demande ser conscientes de los cambios del sistema general y cómo esto ha afectado a la docencia. Estos cambios han sido analizados por varios autores. Weber y Habermas, por ejemplo, (aunque con perspectivas y valoraciones distintas) ven en la racionalización la clave de los mismos. Desde una perspectiva del poder, Foucault vio la trasmutación del sistema en las sociedades disciplinarias; en la misma línea Deleuze denomina sociedades de control a las que le suceden a aquéllas.

El ser humano - con su rostro, su historia y su nombre propio - es una entidad propia del mundo de lo cotidiano, de la vida, de la comunidad más que de la sociedad. No son pocos los que han abordado esta cuestión: Tönnies tal vez fue el primero en distinguir entre sociedad y comunidad. Por su parte Habermas distingue - siguiendo a Schütz entre otros - el mundo de la vida y el sistema. El problema de las sociedades modernas es la "colonización" del mundo de la vida por el sistema.

Pero la racionalización está asociada a la hegemonía del sistema sobre el mundo vital. El rostro pierde nitidez y, en consecuencia, es borrado paulatinamente por el sistema ya que éste viene a sustituir aquel entorno que lo hace posible y necesario. En cualquier sistema ecológico toda entidad necesita un conjunto de condiciones en precario equilibrio que la torna posible y necesaria. Son necesarios docentes con rostro para una educación del rostro humano, donde los que más cuenten sean las personas y no las funciones o roles. El rol es esa máscara que la sociedad nos impone - y que la asumimos - detrás de la cual escondemos nuestro rostro - ese sí mismo de carne y hueso que no es ni el sujeto de la acción dramática ni el sujeto trascendental, ambos sin rostrol -. Según Berger y Luckmann (1995) los roles representan el orden institucional. Rubem Alves (1985) afirma que los educadores con rostro van desapareciendo progresivamente, pues el sistema ha generado condiciones que no los hacen posibles ni necesarios. Las nuevas condiciones de las 
sociedades capitalistas posindustriales parecen constituir el hábitat ideal de profesores sin rostro ni memoria.

Son elocuentes las palabras de Camus - recuperadas por Álvarez-Uría (1995) aludiendo a su etapa escolar. Allí el educador es recordado con nombre propio:

En las otras clases les enseñaban sin duda muchas cosas, pero un poco como se ceba un ganso. Les presentaban un alimento ya preparado rogándoles que tuvieran a bien tragarlo. En la clase del señor Germain, sentían por primera vez que existían y que eran objeto de la más alta consideración: se los juzgaba dignos de descubrir el mundo (CAMUS, apud ALVAREZ-URÍA, 1995, p. 58).

El autor ve en esas palabras la definición de la verdadera educación:

La diferencia entre un maestro y un funcionario profesional de la enseñanza no puede estar aquí mejor definida. El profesional trasmite conocimientos amalgamados y seriados, mientras que el maestro comunica sobre todo una implicación en la búsqueda de la verdad (ALVAREZ-URÍA, 1995, p. 58).

El profesor-educador pertenece al mundo de la vida, es previo a la racionalización de las instituciones; antes de que se lo hubiera institucionalizado la sociedad ya lo había instituido. La institucionalización lo fue borrando en favor de la "fabricación" en serie de los profesores-funcionarios. Nuestras escuelas - esos espacios racionalizados definidos por el sistema - se han convertido en su hábitat.

Parte del problema más íntimo de la enseñanza contemporánea en las sociedades capitalistas occidentales tiene que ver con la "pérdida del rostro". Sin rostro estamos imposibilitados de llegar al verdadero sí mismo de cada uno, quedando irremediablemente perdidas parte de las cuestiones que nos definen: el afecto, los sentimientos, los sueños y los deseos.

Sin rostro - en tanto protagonistas de un rol - lo único que nos queda es la cara.

El rostro no puede florecer, como veremos, en el rol (...) nuestro hombre tiene cara, pero no posee rostro (...) La cara se ordena gracias a la cosmética (de kosmos, "orden" en griego), y está completamente contextualizada dado que es objeto de un papel social (MÈLICH, 1994, p. 97).

Este "síncope del rostro" requiere la acción decidida de todos, especialmente de los educadores a quienes aún les queda la posibilidad de la palabra: ese único instrumento con el cual trabaja, sin dejar de lado los aspectos afectivos, como el "otro significante". "Existen ciertamente buenos motivos para creer que, sin esa adhesión emocional a los otros significantes, el proceso de aprendizaje sería difícil, cuando no imposible" (BERGER; LUCKMANN, 1995, p. 167).

\section{Deseo y sociedad: ¿domesticación o fuga?}

Los estudiantes, en su gran mayoría, no aprenden, entre otras cosas por la sencilla razón de que no desean lo que la escuela les ofrece. Y los pocos que lo hacen parecen haber hipotecado con ello su propio placer. No se trata de que el placer sea la meta de todo proceso pedagógico - educar, obviamente, no es entretener: el aprendizaje requiere un 
esfuerzo -; sin embargo no hay aprendizaje profundo, significativo, sin esa "recompensa interna" que proporciona el placer. Aprender - ese impulso natural de la especie humana en las escuelas hoy no es algo placentero, lo cual constituye una gran paradoja.

Reivindicando el placer en la educación - y el deseo se activa ante su perspectiva de cumplimiento - Hugo Assman afirma: "Necesitamos reintroducir en la escuela el principio de que toda morfogénesis del conocimiento tiene algo que ver con la experiencia del placer" (ASSMAN, 1998, p. 29) ${ }^{1}$. En efecto, al parecer, la ausencia del placer determina que el aprendizaje se reduzca a un proceso meramente instruccional o informativo (aspecto que reviste cada vez más importancia en la educación) dejando de lado la reinvención y la construcción personalizada del conocimiento. El aprendizaje profundo siempre viene acompañado de la sensación de placer, entre otras razones porque se trata de un proceso que tiene una inscripción corporal, no solamente intelectual. El conocimiento humano nunca es pura operación mental, ya que toda activación de la inteligencia está entretejida de emociones, deseos y placeres.

No se aprende aquello que no se desea. Si asumimos esta premisa deberíamos como profesores tener firmemente en cuenta esta cuestión. Por otra parte hablar del deseo no es hablar de un concepto unívoco. Por lo pronto pueden haber posiciones al respecto tan distantes como las del psicoanálisis freudiano - que ven al deseo enraizado en las relaciones parentales en el seno familiar - y las del estructuralismo deleuzeano -para el cual el deseo es producción social -.

Para la concepción clásica del psicoanálisis freudiano, el complejo de Edipo matriz donde se genera el deseo - es una suerte de sentimiento infantil neurótico cuya génesis se encuentra en la relación entre padres e hijos.

El hijo quiere eliminar al padre y ocupar su puesto en la cama matrimonial. A partir de ese axioma inicial, el psicoanálisis ha quedado prisionero de un familiarismo impenitente, en la que el deseo se genera en una instancia parental denominada por Freud complejo de Edipo (DÍAZ, 2002, p. 136).

El sentido de esa relación estaría determinado por el hijo. Según Freud (1996) se puede afirmar que el complejo de Edipo es clave de las neurosis y constituye su elemento esencial ya que en él la sexualidad infantil llega a su punto culminante.

Sin embargo, desde el punto de vista de Deleuze y Guattari (1985) en sus estudios sobre el deseo y el capitalismo tardío, la interpretación de este complejo se invierte: Edipo se explica más por la paranoia del adulto que por la neurosis infantil. En otras palabras, lo determinante en el sentido de la relación son los padres, quienes a su vez forman parte de una sociedad que los condiciona. Aún fuera del enfoque estructuralista, la psicología ya había cuestionado la tesis del innatismo infantil de los impulsos. Wolf (1963) - aunque sin incorporar los factores sociales y manteniendo la determinación de lo parental y familiar en el origen de estos impulsos - en 1947 afirmaba que

[...] suponía Freud que el impulso en que se basa el complejo de Edipo era innato, teoría que ha levantado muchas objeciones. Sin embargo, no necesitamos suponer que dichos impulsos sean innatos, sino que pueden ser condicionados por los progenitores mismos. El padre puede proyectar su ideal de la mujer sobre la niñita y la madre su ideal de hombre sobre el varoncito (WOLF, 1963, p. 266-267 - Destacados míos).

Se podría decir que los hijos vienen al mundo y se encuentran con un campo social (que no han elegido) -constituido, entre otras cosas, por prácticas, discursos, economía, formas de vida y fantasías de los adultos- que define sus estados y sus deseos como 
sujetos. Como plantea Esther Díaz - a quien tomo como base para gran parte de lo que sigue en este apartado -: "No habría, pues, como pretende el psicoanálisis, una primacía de las relaciones parentales en la conformación de los sujetos. Estas relaciones se inscriben en una sociedad que las determinan" (DÍAZ, 2002, p. 137).

El deseo es entonces, desde esta perspectiva, una producción social. En lo "macro" el deseo es codificado por el poder, desde donde se busca "interpretar" el deseo de aquellos sobre los que se ejerce dicho poder. En su codificación se busca darle una representación para que el deseo se haga conciente y, con ello, se torne manejable, previsible y, en cierta medida, "desactivado" para el cambio. El deseo, en este caso, funciona a favor del sistema: "Es de gran utilidad para quienes ejercen densamente poder, que las personas se apeguen a ciertas representaciones del deseo. Es en función de esas representaciones, que es efectivo el marketing" (DÍAZ, 2002, p. 139). Se trata de una producción molar, macrofísica, totalizante, aglutinada según los intereses del poder hegemónico.

En lo "micro" el deseo tiende a estar en "estado puro", no tiene representación, no tiene objeto, es "ciego", simplemente desea (no importa el objeto del deseo aquí). Se trata de una producción molecular, microfísica, singularizante, esparcida por los complejos entramados del cuerpo social.

Ahora bien, el deseo puede ser manipulado para ejercer dominio sobre las personas; en ese caso se lo rotula, se lo etiqueta, se le pone nombre (aquí importa el objeto del deseo). Los sujetos, en este caso, son inconscientes de que el deseo les fue impuesto, aunque se comporten como si "supieran" lo que quieren. Según Deleuze y Guattari, en el capitalismo se codifica el deseo como mercadería para ser consumida. De este modo el sistema capitalista se ve beneficiado doblemente: primero, porque en la producción deseante se fortalece el dispositivo económico neoliberal, y segundo, porque homogeniza borrando las diferencias que se supone son fuente de conflictos (Díaz, 2002).

Por otra parte, existe una multiplicidad de "modos de ser" en relación al deseo que cada uno de nosotros concentra. En ese sentido nuestro deseo lo vamos constituyendo a partir de fragmentos de estímulos que orientamos hacia lo que creemos es el objeto de nuestro deseo (que no es más que la representación de algo que por sí mismo es irrepresentable). En otras palabras: el deseo siempre se lo vive en relación a algo, se lo representa porque está codificado socialmente. No podemos concebirlo sin esa representación donde se acumula o "satura" el deseo - que en estado puro no tiene objeto concreto y es errático - posibilitando de esa manera el mejor control social. No habría posibilidad de manejar a aquella persona cuyo deseo es errático, sin objeto definido.

El deseo en estado puro, sin codificación - deseo en sí mismo - es nómade, inconsciente y crecientemente potenciado, alimentado por esos fragmentos libidinales a los que hacíamos referencia. Cuando pasa a la conciencia, lo hace en relación a "objetos" o puntos de conexión en los que habitualmente anclamos nuestro deseo.

El deseo concebido de esa manera circula plenamente por la sociedad, es una fuerza productiva que puede promover cambios positivos. Deleuze y Guattari proponen la posibilidad de cambios a partir de las instituciones, los grupos o las comunidades mediante el análisis y el cambio continuo, molecularizando, sacando el deseo de la vida privada y devolviéndole su carácter nómade, evitando la domesticación.

El capitalismo en su última versión ha sometido el deseo de las masas - en su proceso de codificación particular - a una organización que está al servicio del consumo por el consumo mismo. Deleuze y Guattari en El Anti-Edipo proponen el esquizoanálisis como alternativa militante de resistencia que, entre otras cosas, debe buscar líneas de fuga o distanciamientos entre lo libidinal molecular y las máquinas sociales molares, que desactiven la producción del deseo y de sujetos (en ese sentido la esquizofrenia es la 
"salud", no la "enfermedad"). Para la jerga deleuzeana lo esquizofrénico sería la carga libidinal que escapa a las codificaciones preestablecidas, y lo paranoico la captura por parte del poder de dichos flujos. "La esquizorenia no es pues la identidad del capitalismo sino su diferencia, su separación y su muerte" (DELEUZE; GUATTARI, 1985, p. 254).

Se trata de desentrañar

[...] teóricamente las instancias con las que la producción social encubre su organización de la producción libidinal. (...) de hacer el mapa de la sociedad capitalista. Pero no como una totalidad, sino en las distintas instituciones en las que dicha sociedad se actualiza. El esquizoanálisis (o análisis institucional) es pragmático, intenta liberar las codificaciones impuestas desde el poder dominante, para que afloren intensidades desterritorializantes. (DÍAZ, 2002, p. 144).

\section{Una pedagogía del deseo: ¿aprender a desear para desear aprender? ${ }^{2}$}

Por lo dicho vemos que el desafío de atender la cuestión del deseo en la educación - especialmente en la que nos convoca, la escolarizada - tiene dificultades no menores. Siendo la escuela parte de la maquinaria estatal de constituir sujetos-sujetados (al decir de Foucault, recíprocamente tributario de Deleuze), ¿cómo atender a esta demanda desde una práctica pedagógica que se conciba como un intento colectivo de lucha por la autonomía, el crecimiento personal y la dignidad humanas?, ¿cómo contribuir a la construcción de genuinas líneas de fuga desde el aula y la escuela? Estas y otras inquietudes que se levantan a la luz de lo planteado hacen eco en las palabras de Philippe Meirieu:

Entre la indiferencia y la locura, la renuncia a tener la más mínima influencia sobre el deseo ajeno y la voluntad de controlarlo, ¿queda, acaso, todavía un lugar para una "gestión pedagógica del deseo", y cómo puede escapar de las divagaciones que la amenazan? (MEIRIEU, 2002, p. 95).

Al final, si partimos de que no se aprende verdaderamente algo que no se desea, la explicación de por qué no aprenden los estudiantes parece ser fácil. La cuestión es cómo hacer para que aprendan (de eso se trata, para eso los profesores nos definimos). ¿Es posible hacer que los estudiantes deseen aprender - los conocimientos, la cultura - en las escuelas? ¿cómo?

Parecería que la salida más fácil que se le ha dado al asunto es ignorar el deseo. Para eso es necesario suponer que el individuo puede decidir si está dispuesto, en nombre de un interés superior, a renunciar a sus caprichos del momento. Al ignorar el deseo en la enseñanza se lo deja "librado a la maquinaria codificadora social", por así decirlo, actuando masivamente, con lo cual sólo aprenderán pocos: aquellos que hayan comprendido esa educación como deseable para sí mismos al punto de sacrificar otros deseos más inmediatos. El resto (la mayoría) seguirá otros deseos - en principio igualmente válidos para sí mismos -, aquellos inmediatos que no representan aparentemente renuncia alguna (y a menudo codificados por los mass-media). Al parecer no se trata, como bien lo señala Meirieu (2002), de una elección entre razón en contra del deseo; tampoco de una elección racional entre dos deseos antagónicos. En el fondo, ignorar la cuestión del deseo supone resignarse a las condiciones de desigualdad en que el deseo por determinados objetos culturales es "distribuido" socialmente mediante la maquinaria codificadora del sistema. 
Tal vez, entonces, no habría que ignorarlo, pero ¿es posible (y lícito) "producirlo", "despertarlo" o "hacerlo surgir" desde la práctica educativa?, ¿cómo? Una posición más rousseauniana sería esperar que el deseo por aprender ciertos "objetos culturales" que la escuela ofrece surja naturalmente, suponiendo que el mismo ya está latente en todos los estudiantes. Sin embargo esto supondría en algunos casos renunciar a la propia tarea educadora, o en su defecto omitirse de una responsabilidad socialmente definida y asumida por los profesores: la de enseñar, haciendo que todos los estudiantes se apropien de dichos "objetos culturales".

No se trataría de ignorar el deseo proponiendo un saber que, en tal caso, debería ser prescriptivo; ni tampoco hacer una suerte de "fetichización" del deseo -habitualmente codificado por lo social- sometiendo todo saber a sus caprichos. En ambos casos el docente no tiene nada que hacer en el ámbito de los deseos -precisamente ese "casi nada esencial" de nuestro acápite -, todo quedaría ampliamente determinado por el sistema de expectativas sociales y de los procesos de identificación que él hace posibles y fuera de su alcance.

Por otra parte, ¿cuál es el criterio objetivo - lícito, no arbitrario - a partir del cual los profesores puedan determinar cuáles son los deseos "profundos" o "necesarios" y los "superficiales" o "innecesarios"?

Hay que inventar. Por lo pronto parecería que abrir nuevas líneas de fuga exige anclar el proyecto pedagógico al deseo - "superficial" o no -. Esto contribuiría paulatinamente a la generación de nuevos deseos que permitan la construcción de proyectos culturales distanciados de las determinaciones del poder (o más precisamente del poder dominante de la sociedad). Al parecer los desafíos serían distintos para las diferentes materias y contenidos de aquellos programas en los que, por su naturaleza específica, el tratamiento del deseo no sería el mismo ni siempre posible. Por otra parte, los intentos de articular el conocimiento escolar a los intereses inmediatos de los estudiantes a menudo generan una seducción inicial que termina tan pronto ellos perciben que el "objeto" de su deseo es mero soporte para el desarrollo de los "objetos" escolares.

Tampoco la cuestión implica optar entre un ámbito donde el deseo es posible pero la cultura se encuentre ausente o viceversa (en ese sentido, ¿de qué sirve la escuela, rebosante de deseo, pero vacía de contenidos? - ése es el problema central -). En ambos casos hay un hiato entre deseo y cultura, con lo cual el aprendizaje de la cultura se vería comprometido.

Si la tarea fundamental para el aprendizaje de los estudiantes es hacer surgir el deseo por la cultura, el conocimiento, el saber que pretendemos enseñar, entonces estos objetos deberían participar de ciertas cualidades que los tornarían "deseables" para esos jóvenes. Habría que preguntarse sobre qué cualidades revisten los objetos de deseo. Aquí entramos en un campo donde es necesario especular, probar, ensayar, crear... Una cosa parece cierta: son demasiado complejos los vericuetos de los flujos deseantes en el entramado social, y oscuros los laberintos del sujeto deseante como para una afirmación categórica acerca de la "gestión pedagógica" del deseo. Dicha complejidad parece resistir a toda reducción teórica. No obstante, como vimos, desde la perspectiva social el deseo puede ser "producido" y para ello debe ser codificado, o sea, debe tener un "objeto" definido y su correspondiente designación en el lenguaje. Por lo tanto lo deseable debe ser pasible de ser nombrado, de ser conocido en parte (esto no implica anular el requisito de una carencia); se trata de la necesidad de "anclar" - aunque provisoriamente - los flujos sociales libidinales en un "objeto" arbitrario. En ese sentido no se desea lo que no se puede conocer ni codificar (por lo que conocer en parte al "objeto" parece ser un prerrequisito para que se "active" el deseo); pero también parece cierto que, en el campo de lo cognitivo, 
no se desea con más énfasis aquello que se considera plenamente conocido (lo que desaconsejaría el pleno conocimiento del "objeto" a desear). Se instala aquí una paradoja del deseo, que en términos más sencillos consiste en que su "objeto" debe ser a la vez conocido y desconocido (en otro plano - y en términos psicoanalíticos - sería la relación del deseo con una carencia y la promesa de su satisfacción), "es preciso adivinar sus formas, entrever el secreto, pero debe permanecer escondido y el misterio no debe ser develado" (MEIRIEU, 2002, p. 100).

En ese sentido, tal vez una posibilidad de acción para los profesores consista, como lo propone Meirieu, en "crear el enigma", o sea, reinstalar el misterio de lo conocido y a la vez no conocido - que por eso mismo mantiene la promesa de la satisfacción en su acceso pleno -, una distancia prudente entre lo conocido y lo por conocer, aquello que impulsa su búsqueda, despierta el deseo por la promesa de su satisfacción. Supone una nueva forma de relacionarnos con los contenidos de la enseñanza.

Los docentes deberíamos, entre otras cosas, esforzarnos por crear enigmas: presentar lo suficiente para que los estudiantes entrevean el interés y la promesa de un "secreto" a descubrir. ¿Tal vez no sea esa la verdadera fuerza que impulsa a aquellos que se han lanzado a la aventura del descubrimiento? Habría que suspender (no eliminar) la explicación y hacer surgir el deseo; la explicación - a la que los docentes parecen rendirse con más facilidad que a la pregunta - anticipa la demanda y con ello mata al deseo antes de nacer. No se trata de una actitud controladora del saber de los demás, ni de una mera técnica propia de un didactismo activista, sino de promover seriamente el deseo y, a la vez, abrir espacios/tiempos de libertad.

He ahí una tarea para los profesores: definir lo pertinente a ser enseñado y dosificarlo; ¿cuánto de dificultad y de accesibilidad deben tener las tareas escolares? Debe haber perspectiva de logro, ¿acaso no se vive lo inaccesible, a lo sumo como desafío inicial, pero al no obtener resultados satisfactorios concretos se abandona pronto la tarea? Asimismo ¿no se abandona aquella tarea que no convoca por ser demasiado fácil o accesible, que ya no aporta nada a lo que ya se sabe? Habría que buscar, para cada caso, una "distancia óptima" y no privar a los estudiantes de ese espacio/tiempo de búsqueda dándoles aquello que deberían encontrar por sí mismos. Esto puede sonar trillado. En efecto, los movimientos de innovación pedagógica del siglo XX - deudores de los ideales deweyanos - lo han promovido hasta el cansancio, pero desde una perspectiva pragmática y de un didactismo activista apolítico y pretendidamente neutral. "Promover un enigma con el saber: promover un saber con el enigma” (MEIRIEU, 2002, p. 101).

En todo caso

[...] no existe ninguna fórmula mágica para contagiar la pasión por el conocimiento, si se exceptúa que no podrá trasmitirla quien no se sienta a sí mismo con capacidad para la sorpresa y el descubrimiento de lo desconocido. La transmisión de la fascinación por la verdad no tiene tanto que ver con el saber, cuanto con la conciencia de la ignorancia y el deseo de salir de ella (ÁLVAREZ-URÍA, 1995, p. 58).

Ahora bien, el deseo se "activa", por así decirlo, ante la perspectiva del placer prometido por él. Al parecer el conocimiento emerge en su dimensión vitalizadora, profunda, cuando tiene alguna vinculación con el placer. En ese sentido es necesario reconocer la inscripción corporal/espiritual del conocimiento. Se aprende con "el cuerpo y la cabeza", y esto no es mero lenguaje figurativo; al decir de Assman (1998) es reconocer el carácter pluri-sensual del conocimiento ligado al interjuego de certezas e incertezas en los procesos adaptativos que la vida nos impone. Dichos procesos adaptativos, lejos de 
arrojarnos a la pasividad, son eminentemente creativos y se desarrollan con la intervención del sujeto.

La relevancia del placer en el aprendizaje es señalada por una comprensión del mismo que lo concibe en la coincidencia entre procesos vitales y procesos cognitivos. En ese sentido el concepto de "morfogénesis del conocimiento" - constituida por niveles emergentes a partir de procesos auto-organizativos de la vida - nos podría ayudar en dicha comprensión. Por eso todo conocimiento tiene una inscripción corporal y se apoya en una compleja interacción sensorial.

El profesor, en tanto sujeto cognoscente, es/debe ser, por así decirlo, una "prueba viviente" del placer prometido por el conocimiento parcial del objeto (esto tiene que ver con el deseo de aprender traducido al deseo de enseñar); comparte con el estudiante, por lo tanto, la misma naturaleza, se torna su cómplice en esta búsqueda. Desde esta perspectiva educar es seducir, y se seduce con el corazón.

\section{Exoducción (que pudo ser exordio): Odiseo infartado}

En aquel relato fundacional del pensamiento occidental, Homero - quien se ubica en la transición entre mythos y logos - cuenta cómo Odiseo vence las fuerzas míticas a través de la astucia o el ingenio. El héroe aún se debatía entre las fuerzas irracionales del corazón, por un lado, y la acción racionalizadora del logos en su astucia, por otro. Es necesario conquistar el yo interno como unidad, venciendo a los mitos. Pero vencer a las fuerzas mitológicas demandaba pagar un precio: someter el corazón a la razón. En efecto, al comienzo del canto XX, Homero cuenta cómo se realiza esta operación:

El héroe sintió conmovérsele el ánimo en el pecho, y resolvió muchas cosas en su mente y en su corazón, (...); y en tanto el corazón desde dentro le ladraba. Como la perra que anda alrededor de sus tiernos cachorrillos ladra y desea acometer cuando ve a un hombre a quien no conoce, así, al presenciar con indignación aquellas malas acciones, ladraba interiormente el corazón de Odiseo. Y éste, dándose golpes en el pecho, reprendiólo con semejantes palabras.

- Aguanta, corazón, que algo más vergonzoso hubiste de soportar aquel día en que el cíclope, de fuerza indómita, me devoraba los esforzados compañeros; y tú lo toleraste, hasta que mi astucia nos sacó del antro donde nos dábamos por muertos!

Así dijo, increpando en su pecho al corazón que en todo instante se mostraba sufrido y obediente mas Odiseo revolvíase ya a un lado, ya al opuesto (HOMERO, 2004, p. 204-205).

El sujeto - como unidad idéntica a sí misma - aquí es "inventado". Una atrevida exégesis del texto permitiría sostener que el yo idéntico sería considerado por Homero sólo como resultado del dominio de la naturaleza interna del hombre. Estamos frente a la génesis del individuo occidental, “...el héroe (...) se revela como prototipo del individuo burgués, cuyo concepto se origina en aquella autoafirmación unitaria de la cual el héroe peregrino proporciona el modelo prehistórico." (ADORNO; HORKHEIMER, 2001, p. 97).

Este yo idéntico, la persona en sí misma, aún tiembla en el héroe reducido a una cosa: el cuerpo luego de que el corazón ha sido castigado en él. El afecto es comparado al animal - que sólo puede gemir o ladrar - mientras la mente - otra fuerza interior que se agita independientemente al igual que aquélla (una en el pecho, otra en la cabeza, es de suponer) - habla, o sea se expresa a través del logos (palabra o razón, para los griegos). En 
esa disputa sale victoriosa la razón frente al corazón, que calla ante los golpes en el pecho. Adorno y Horkheimer (2001), en uno de sus más memorables textos, ${ }^{3}$ ve en la Odisea una alegoría premonitoria de la Ilustración dialéctica.

El sujeto dividido aún y obligado a emplear la violencia tanto contra la naturaleza en sí mismo como contra la naturaleza exterior, "castiga" a su corazón obligándole a la paciencia y prohibiéndole, en aras del futuro, el presente inmediato. Golpearse el pecho se ha convertido después en un gesto de triunfo: el vencedor expresa en él que su victoria es siempre una victoria sobre su propia naturaleza. La obra es llevada a cabo por la razón autoconservadora (ADORNO; HORKHEIMER, 2001, p. 101).

Ese gesto de triunfo del hombre moderno que se golpea el pecho es el optimismo autocomplaciente de una sociedad racionalizada. Es curioso como ante el fracaso, la desazón y el sentimiento de culpa, algunas personas parecen recriminarse golpeándose repetidamente con la palma de las manos en la cabeza. ¿Es la contrapartida de aquel gesto de victoria? ¿Estarían ratificando con ello el gesto de Odiseo? El hecho es que preferimos oir la voz de la razón que atender a los ladridos del corazón.

La denuncia frankfurtiana representada por Adorno se refiere a la degradación de la razón en un mundo administrado por la técnica. Sin embargo es el corazón el que hemos callado - y con ello los afectos, los sentimientos y deseos -; el resultado es el proceso racionalizador identificador que opera binariamente por exclusión del otro.

La educación actual parece orientada obsesivamente hacia la razón y el intelecto. Se aleja progresivamente de aquella aspiración pestalozziana de una educación que tuviera en cuenta "la cabeza, el corazón y la mano". La formación científica e intelectual, y la capacitación técnica e instrumental - más articuladas con los requerimientos del sistema parecen ofuscar el interés por una educación integral, del rostro humano, articulada con los sueños, afectos y deseos de las personas y su sociedad de referencia.

Es el eclipse del corazón ${ }^{4}$, producto tal vez de aquel infarto homérico, que parece arrojarnos a un camino sin regreso. En nuestras sociedades no es tanto el dolor lo que crece - y en principio lo que preocupe, pues éste también pertenece a la esencia de la vida (la educación parece prepararnos para soportarlo) - sino la indiferencia hacia el dolor y la indulgencia frente a la injusticia. Eso debería preocuparnos. Nuestras aulas deberían ser oportunidades para pensar y aprender a pensar sobre estas y otras cuestiones y prepararnos para no ser indiferentes, o sea, para intervenir. Pero esto es imposible cercenando el cuerpo $\mathrm{y}$ atrofiando los afectos, los placeres y los deseos.

\section{REFERENCIAS}

Adorno, Theodor; Horkheimer, Max. Dialéctica de la Ilustración. Madrid: Trotta, 2001. Alvarez-Uría, Fernando. Escuela y subjetividad. Cuadernos de Pedagogía. Barcelona, n. 242, p.56-64, 1995.

Alvez, Rubem. Conversas com quem gosta de ensinar. Sao Paulo: Cortez Associados, 1985.

Assman, Hugo. Reencantar a educação. Rumo à sociedade aprendente. Petrópolis: Vozes, 1998.

Berger, Peter; Luckmann Thomas. La construcción social de la realidad. Buenos Aires: Amorrortu, 1995. 
Deleuze, Gilles; Guattari, Felix. El antiedipo: capitalismo y esquizofrenia. Buenos Aires: Paidós, 1985.

Díaz, Esther. Posmodernidad. Buenos Aires: Biblos, 2002.

Freud, Sigmund. Los textos fundamentales del psicoanálisis. Buenos Aires: Altaya, 1996.

Homero. La odisea. México, D.F.: Leyenda, 2004.

Mèlich, Joan-Carles. Del extraño al cómplice. La educación en la vida cotidiana. Barcelona: Anthropos, 1994.

Meirieu, Philippe. Aprender sí. Pero ¿cómo? Barcelona: Octaedro, 2002.

Restrepo, Luis Carlos. Ecología humana. Una estrategia de intervención cultural, San Pablo editor, Bogotá, 2002. Disponible en: $<w w w . l u i s c a r l o s r e s t r e p o . c o m>$. Consultado el: 8 de marzo de 2008.

Wolf, Werner. Introducción a la Psicología. México: F.C.E, 1963.

Dados do autor: Augusto Lara 1652, Rivera, Uruguay, CP 4000joniocano@gmail.com.

\footnotetext{
${ }^{1}$ Original en portugués, la traducción es mía.

${ }^{2}$ En gran parte de este apartado me baso en Meirieu (2002).

${ }^{3}$ El texto es "Excursus I: o mito e ilustración" que pertenece a la celebrada obra Dialéctica de la Ilustración escrita en coautoría con Horkheimer. La cita es tomada de un jugoso pie de página donde analiza la cuestión.

${ }^{4}$ Parafraseamos aquí una de las obras más importantes de Horkheimer, cuya denominación original es "Eclipse de la Razón".
}

Aprovado em: $\quad$ 09/02/12 